\title{
Research Paper: Insulin within the Arcuate Nucleus Has Paradoxical Effects on Nociception in Healthy and Diabetic Rats
}

Hossein Khaleghzadeh-Ahangar ${ }^{1,2 *}$ (D), Forouzan Sadeghimahalli ${ }^{3}$ (D), Shaghayegh Khandan ${ }^{2}$ (i), Sima Shahabi ${ }^{1,2}$ (D), Aliakbar Moghadamnia ${ }^{2,4}$ (C)

1. Department of Physiology, School of Medicine, Babol University of Medical Sciences, Babol, Iran.

2. Neuroscience Research Center, Health Research Institute, Babol University of Medical Sciences, Babol, Iran.

3. Departement of Physiology, School of Medicine, Mazandaran University of Medical Sciences, Sari, Iran.

4. Department of Pharmacology, School of Medicine, Babol University of Medical Sciences, Babol, Iran.

\begin{tabular}{|l|l|}
\hline $\begin{array}{c}\text { Use your devic to scan } \\
\text { and read the article online }\end{array}$ & $\begin{array}{l}\text { Cittation: Khaleghzadeh-Ahangar, H., Sadeghimahalli, F., Khandan, Sh., Shahabi, S., \& Moghadamnia, A. (2020). Insulin } \\
\text { within the Arcuate Nucleus Has Paradoxical Effects on Nociception in Healthy and Diabetic Rats. Basic and Clinical Neurosci- } \\
\text { ence, 11(6), 727-736. http://dx.doi.org/10.32598/bcn.11.6.1983.1 } \\
\text { dof http://dx.doi.org/10.32598/bcn.11.6.1983.1 }\end{array}$ \\
\hline
\end{tabular}

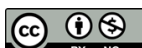

Article info:

Received: 11 Aug 2019

First Revision: 15 Sep 2019

Accepted: 08 Nov 2019

Available Online: 01 Nov 2020

Keywords:

Arcuate nucleus, Insulin, Hot plate, Tail-flick, Acute pain

\section{A B S T RA C T}

Introduction: Broad neural circuits originate from the hypothalamic arcuate nucleus and project to many parts of the brain which are related to pain perception. Insulin receptors are found in the arcuate nucleus. Since nociception may be affected in type 1 diabetes, the present study aimed to investigate the intra-arcuate nucleus insulin role in pain perception in streptozotocin (STZ)-induced diabetic and healthy rats.

Methods: Regular insulin was microinjected within the arcuate nucleus and the pain tolerance was measured using the hot plate and the tail-flick apparatus in diabetic rats.

Results: The results showed that the arcuate nucleus suppression with lidocaine could increase thermal nociception in non-diabetic animals. Also, insulin within the arcuate nucleus decreased the acute thermal pain perception in these animals. STZ-induced diabetes produced hypoalgesia which the latency of these tests, progressively increased over time after induction of diabetes. Also, in the same animal group, intra-arcuate injection of insulin reduced the latency of nociception.

Conclusion: Intra-arcuate insulin has paradoxical and controversial effects in healthy and diabetic rats' nociception. These effects seem to be due to the insulin effect on releasing proopiomelanocortin and its derivatives.

\section{* Corresponding Author:}

Hossein Khaleghzadeh-Ahangar, PhD.

Address: Department of Physiology, School of Medicine, Babol University of Medical Sciences, Babol, Iran.

Tel: +98 (113) 2199592

E-mail: h.khaleqzadeh@gmail.com 


\section{Highlights}

- The arcuate nucleus inhibition increased thermal nociception.

- Administrating insulin within the arcuate nucleus decreased the acute thermal pain perception.

- Streptomycin-induced diabetes makes thermal hypoalgesia.

- Pain response latency progressively increased over time after induction of diabetes.

- Intra-arcuate injection of insulin reduced the latency of thermal nociception in streptomycin-induced diabetes.

\section{Plain Language Summary}

The arcuate nucleus is a part of the ventral hypothalamus. It secrets endogenous opioids and projects to several parts of the brain involved in pain perception. The arcuate nucleus contains insulin receptors, and it seems that insulin can excite its neuron to secret the endogenous opioids. In type 1 diabetes, insulin secretion decreases. Accordingly, it appears that the arcuate nucleus excitation decreases because of insulin reduction. The present study illustrated that the arcuate nucleus inhibition by lidocaine increases pain feeling, so this nucleus is a pivotal part of pain sensation. Insulin injection inside the arcuate nucleus reduces pain sensation in healthy rats. Also, type 1 diabetes decreases pain sensation, but insulin injection within the arcuate nucleus increases it. This phenomenon is contrary to the results observed in healthy rats. Therefore, it seems that different mechanisms affect arcuate nucleus neurons in healthy and diabetic rats.

\section{Introduction}

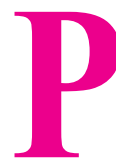

Pain is an undesirable feeling that is due to irritating free nerve terminals. Pain is divided into acute and chronic types. The acute pain is also called sharp pain and electrical pain. The duration of the acute pain following a painful stimulus is about 0.1 seconds. This pain is not felt in deep tissues. Acute pain could be measured using the hot plate apparatus (Carr \& Goudas, 1999).

Sharp or acute pain is induced by heating or mechanical and chemical irritation. This pain may release more chemicals from damaged tissue and over the time this process can increase acute pain intensity (Dickenson, 1995). Acute pain projects to the brain cortex so it can be localized (Treede, Kenshalo, Gracely, \& Jones, 1999).

Pain control is conducted by nonsteroidal anti-inflammatory drugs and opioid anti-pain drugs. Furthermore, the pain can be modulated by endogenic opioid manipulation. Endogenic opioids consist of enkephalins, endorphins, and especially beta-endorphin. It is one of the polypeptides deriving from Pro-Opiomelanocortin (POMC) and its level increases in response to pain (Przewłocki \& Przewłocka, 2001). The arcuate nucleus of the hypothalamus is the main source of the POMC in the brain (Van Houten, Posner, \& Kopriwa, 1980). Beta- endorphin and related peptides derived from the POMC accumulate in the arcuate nucleus neurons in the middle inferior part of the hypothalamus. Broad neural circuits that originate from the hypothalamic arcuate nucleus project to many parts of the brain that have a role in pain control such as hypothalamus nuclei, limbic system, raphe nucleus, and some pons nuclei. The central POMC system has a role in the antinociceptive process (Sim \& Joseph, 1991). Lesion of the arcuate nucleus of the hypothalamus as the main POMC source of the brain causes weakness in the antinociceptive process after anxiety and decreases the antinociceptive process due to electrical irritating of the periaqueductal gray area that exists in beta-endorphin nervous terminals. In other words, betaendorphin neurons terminals are modulated in both the lateral ventricles and in the spinal cord that makes an analgesic process, and this function is blocked by naloxone (Van Houten et al., 1980; Yamamoto, Nozaki-Taguchi, \& Chiba, 2002).

Some kinds of diseases would affect nociception. One of them is diabetes that today many people suffer from it. This is one of the most important metabolic diseases (Lorenzo et al., 2006). Sensory and neurosecretory nociceptor functions are sensitized in diabetes (Fuchs, Birklein, Reeh, \& Sauer, 2010). Insulin-dependent diabetes (type 1 diabetes) may display signs of hyperalgesia and allodynia (Courteix, Bardin, Chantelauze, Lavarenne, \& Eschalier, 1994). Intra- 
cerebroventricular (ICV) injection of insulin showed an analgesic effect in the formalin test model of pain (Takeshita \& Yamaguchi, 1997). In the tail-flick test, the nociceptive response latency progressively increased during chronic diabetes (Bitar \& Pilcher, 1997). The pressure pain threshold during 2 weeks after Streptozotocin (STZ)-induced diabetes decreased. This hyperalgesia was independent of plasma glucose but related to low plasma insulin (Romanovsky, Cruz, Dienel, \& Dobretsov, 2006). Diabetic rats displayed mechanical hyperalgesia by decreasing paw withdrawal thresholds to mechanical stimuli; they also indicated thermal hypoalgesia by increasing tail-flick latencies (Sugimoto, Rashid, Shoji, Suda, \& Yasujima, 2008).

STZ is widely used to induce experimental diabetes in animals. STZ enters the pancreatic B cells via a glucose transporter (GLUT2) and causes alkylation of DNA which leads to DNA damage. As a result of the STZ action, pancreatic beta cells are destroyed (Bayat \& Haghparast, 2015).

The Insulin Receptor (IR) exists in many brain areas, including the arcuate nucleus with high density (Schulingkamp, Pagano, Hung, \& Raffa, 2000; Van Houten et al., $1980)$. Since the arcuate nucleus plays a role in the nociception pathway and possesses the insulin receptor, this study was designed to investigate the arcuate nucleus role and also insulin effect within the arcuate nucleus in acute pain nociception in healthy rats, STZ-induced acute diabetic rats, and also STZ-induced chronic diabetic rats.

\section{Methods}

\subsection{Animals}

Male albino Wistar rats weighing 200-250 g were used for the study. The rats were housed under 12 hours of light and 12 hours of dark conditions. The time was set in which lighting was started at 7:00 AM. During the experiment, the rats had free access to enough food and water. The rats were transferred to the lab space a week before the experiment to let them become familiar with the environment. Each rat was used just once.

\subsection{Drugs}

STZ (Santa Cruz biotechnology Company, Dallas, USA) was freshly prepared and dissolved in cold normal saline immediately before injection. Regular insulin (Exir Pharmaceutical Company, Boroujerd, Iran) and $2 \%$ lidocaine (Aburaihan Pharmaceutical Company, Tehran, Iran) were used.

\subsection{Type 1 diabetes induction}

Animals were divided into 2 groups: STZ-receiving and healthy rats. The diabetes was induced by an intraperitoneal (IP) injection of $60 \mathrm{mg} / \mathrm{kg}$ dose of STZ solution in cold normal saline. Six days after injection, blood samples were collected and serum glucose was measured using spectrophotometry and glucometer. Only rats with blood glucose levels higher than $250 \mathrm{mg} / \mathrm{dL}$ were subjected to continuing the study as diabetic rats. Experimental diabetes also was determined by changing the behavior of animals through polyphagia, polydipsia, polyuria, and weight loss (Bayat \& Haghparast, 2015; Sadeghimahalli, Khaleghzadeh-Ahangar, \& Baluchnejadmojarad, 2019).

\subsection{Experiment design}

Rats were divided into 8 groups each included 6 rats $(\mathrm{n}=6)$. This is the final number of the rats that participated and resulted in the statistical analysis after excluding the troubled ones. The criteria for excluding the subjects from the study were such things as wrong cannulation, rats which their blood glucose was lower than $200 \mathrm{mg} /$ dL after STZ injection, and rats with impaired mobility.

2.4.1. The hypothalamic arcuate nucleus role in acute pain in non-diabetic rats

After a recovery period, one group that contained nondiabetic rats (healthy rats) received $0.5 \mu \mathrm{L}$ of $2 \%$ lidocaine within the hypothalamic arcuate nucleus to investigate this brain structure's role in acute pain.

\subsubsection{The effect of intra-arcuate nucleus insulin mi- croinjection on acute pain in the non-diabetic rats}

After the recovery period, non-diabetic rats received 0.5 $\mu \mathrm{L}$ saline as a drug vehicle (one group) and $0.5 \mu \mathrm{L}$ of three doses of Insulin $(0.02,0.1$, and $0.5 \mathrm{IU})$ within the hypothalamic arcuate nucleus (in three different groups) to investigate the insulin effect within this nucleus on acute pain.

2.4.3. The effect of intra-arcuate nucleus insulin $0.5 \mathrm{IU}$ on acute pain in STZ-induced diabetic rats

The diabetic rats received an intra-arcuate effective dose of insulin ( $0.5 \mathrm{IU})$ to investigate the insulin effect on the acute pain in these animals 1,2, and 3 weeks after diabetes induction. This procedure was done in two different groups (one for the hot plate test and the other one for the tail-flick test). 


\subsubsection{The effect of insulin deficiency on acute pain during the time}

The non-diabetic and insulin-dependent diabetic rats after 1,2 , and 3 weeks of diabetes induction were studied by hot-plate and tail-flick tests to investigate the insulin deficiency on acute pain during the time.

\subsection{Stereotaxic surgery and cannula implantation}

Rats were anesthetized by IP injection of xylazine $(10 \mathrm{mg} / \mathrm{kg})$ and ketamine $(100 \mathrm{mg} / \mathrm{kg})$. After shaving their hair, the rats were fixed into the surgical device. The scalp was cut and to reduce bleeding and local anesthesia, the lidocaine plus epinephrine solution was used. To specify lambda and bregma lines, the area was cleaned using $70 \%$ ethylic alcohol. According to the atlas of Paxinos and Watson (Paxinos \& Watson, 2006), arcuate nucleus coordinates are as follows: $-2.28 \mathrm{~mm}$ to bregma with $9.4 \mathrm{~mm}$ depth from the surface of the skull and in the midline of the skull. The length of cannulas (23 gauge) was considered $12 \mathrm{~mm}$. The length of the needle for microinjection was also $12 \mathrm{~mm}$. The skull was pierced by a dental drill on the determined location. Then, the cannula guide would be placed in the brain on the surface of the nucleus and its upper part was fixed in the skull surface with dental cement. Since the arcuate nucleus is exactly in the middle line and has a small size, the cannula was put in the midline. For more fixation of cement and cannula, small screws (glasses screw) were used which were embedded within the skull bone and dental cement. The opening of the guide cannula out of the skull was blocked with a dental metal needle and it was removed only at the time of microinjection. All instruments were sterilized to prevent infection. After cannula implantation and surgery, the rats were passed a 4-day recovery period.

\subsection{Microinjection}

For microinjection in the nucleus through the cannula, a 12-mm long 30-gauge needle has been joined to a thin polyethylene tube on one side. The other side of the tube was connected to the Hamilton syringe to control the microinjection volume.

\subsection{Thermal acute pain tests}

\subsubsection{Hot Plate test}

The Hot Plate test was implemented as follows: to adapt the animals to the environment and reducing stress, 1 day before starting the hot plate test, the rats were placed on the cold (off position) surface of the hot plate device for 3 minutes to get familiar with the environment. On the test day, the hot plate temperature was set at $52^{\circ} \mathrm{C}$ and the animals were put on it. The reaction time or the time it takes for the animal to respond to pain stimuli was measured in seconds. The reaction time was when the animals were licking their paws or jumping from the hot plate surface that is defined as "pain response latency" and expressed in seconds. The end of this test (cutoff point) was considered 60 seconds to prevent probable animal tissue damages (Erami, Azhdari-Zarmehri, Ghasemi-Dashkhasan, Esmaeili, \& Semnanian, 2012). This test is done for each rat 30 minutes before and about 60 minutes after microinjection. To reduce probable human errors, all tests were done by one person.

\subsubsection{Tail-flick test}

The tail-flick test was run by the tail-flick apparatus (Ugo Basile, Italy). The Tail-Flick Latency (TFL) was calculated on the average of three consecutive tail-flick tests at each time point. The heat stimulus was provided by a light source that projects infrared (IR) light. The IR light was set at an intensity that yields a TFL reaction in the range of 3-4 s (about 55\% of maximal IR intensity). The cut-off point was set $10 \mathrm{~s}$; if the animal failed to flick its tail during 10s, its tail would be removed from the coil to prevent probable damages to the skin. The reaction time between the onset of heat stimulus and the movement of the tail was determined by an automatic sensor. The IR heat was applied about $5 \mathrm{~cm}$ from the caudal tip of the tail (Sadeghi, Reisi, Azhdari-Zarmehri, \& Haghparast, 2013). This test has been done for each rat 30 minutes before and about 60 minutes after microinjection. To reduce probable human errors, all tests were done by one person.

\subsection{Histological verification}

At the end of the study, the rats in each group were decapitated, and to ensure and investigate the microinjection site the brain tissue sections were prepared. The rats that had a defect or a problem in cannulation were excluded from the study.

\subsection{Statistical analysis}

For statistical analyses, the paired-sample t-test and ANOVA test (continued with Newman-Keuls post hoc test) were used to compare the before-after and several group comparisons, respectively. $\mathrm{P}$ values less than 0.05 were considered to be statistically significant. 


\section{Results}

3.1. The hypothalamic arcuate nucleus role in acute pain in non-diabetic rats

To show and confirm the arcuate nucleus role in the pain perception, $0.5 \mu \mathrm{L}$ of $2 \%$ lidocaine was infused within this area. The arcuate nucleus neurons suppression by microinjection of $2 \%$ lidocaine caused increasing in nociception by decreasing the pain response latency in the hot plate test (Figure 1).

3.2. The effect of intra-arcuate nucleus insulin microinjection on acute pain in the non-diabetic rats

To investigate the insulin role within this nucleus on acute pain, $0.5 \mu \mathrm{L}$ of three doses of insulin $(0.02,0.1$, and $0.5 \mathrm{IU}$ ) and saline (as the vehicle) were infused within the arcuate nucleus. Intra-arcuate nucleus insulin dose-dependently increased the pain response latency of acute thermal pain in hot plate test so that for the $0.5 \mathrm{IU}$ group, the t-test demonstrated that the nociception (acute pain threshold/the level of analgesia) decrease was statistically significant $(\mathrm{P}<0.05$; Figure 2$)$.

\subsection{The effect of intra-arcuate nucleus insulin 0.5 IU on acute pain in STZ-induced diabetic rats}

When the thermal acute pain was tested by the hot plate instrument, the t-test displayed that the microinjection of

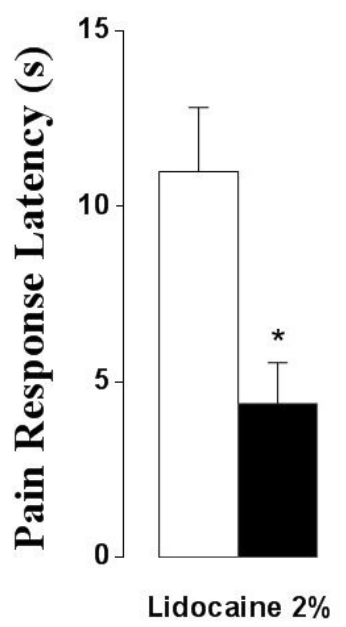

NEUR SCIENCE

Figure 1. Effect of $2 \%$ lidocaine injection in the arcuate nucleus on pain response latency in the Hot Plate test

The white column displays pain response latency before and the black one displays it after lidocaine injection. Each column indicates the Mean $\pm S E M$ value of each group.

${ }^{*} \mathrm{P}<0.05$ in the $\mathrm{t}$-test the effective dose of insulin ( $0.5 \mathrm{IU})$ in the hypothalamic arcuate nucleus in the first week of STZ-induced diabetes led to acute pain increase $(\mathrm{P}<0.01)$. In the next week, this method was performed again and pain response latency decreased in response to insulin; it means that acute pain and nociception were increased $(\mathrm{P}<0.01)$. Similarly, in the third week, the microinjection with the same dosage of insulin caused a reduction in pain response latency and nociception increased in insulin-dependent diabetic rats $(\mathrm{P}<0.05$; Figure 3$)$.

In the tail-flick part, intra-arcuate insulin significantly increased the pain response latency in non-diabetic rats the same as the hot plate result $(\mathrm{P}<0.05)$. Intra-arcuate nucleus injection of $0.5 \mathrm{IU}$ insulin increased the pain response latency in the first week of STZ-induced diabetes but this increase was not statistically significant. In the following weeks in diabetic rats, intra-arcuate nucleus insulin injection decreased the pain response latency so that in the third week, it was significantly decreased $(\mathrm{P}<0.05$; Figure 4$)$.

\subsection{The effect of insulin deficiency on acute pain during the time}

When the pain response latency was compared among non-diabetic rats and at different weeks after STZ-induced diabetes induction, 1-way ANOVA indicated that it was significantly increased after diabetes induction

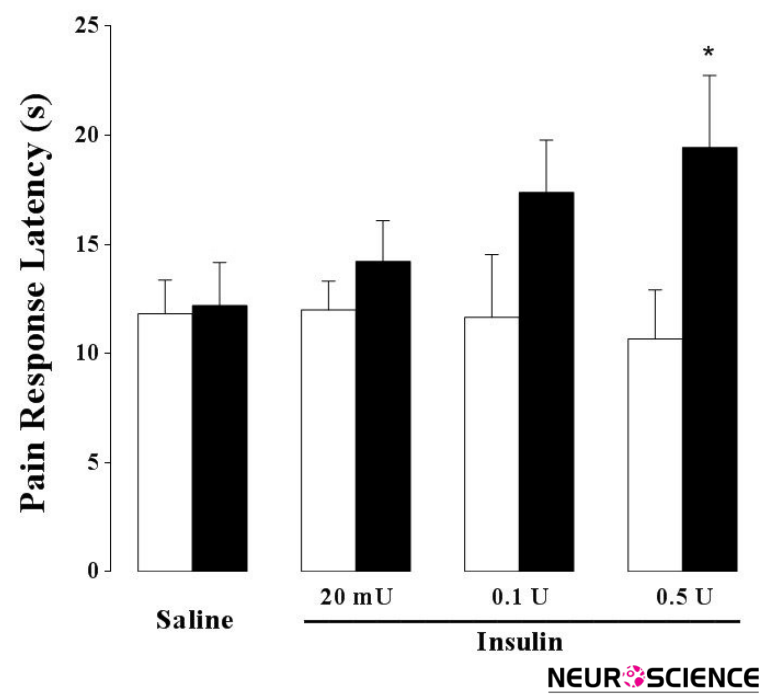

Figure 2. Effect of different doses of insulin $(20 \mathrm{mU}, 0.1 \mathrm{IU}$, and $0.5 \mathrm{IU}$ ) and the vehicle (saline) within the arcuate nucleus on pain response latency in hot plate test in different groups

The white columns display pain response latency before and the black ones display it after insulin injection. Each column indicates the Mean $\pm S E M$ value of each group.

${ }^{*} \mathrm{P}<0.05$ in the t-test. 


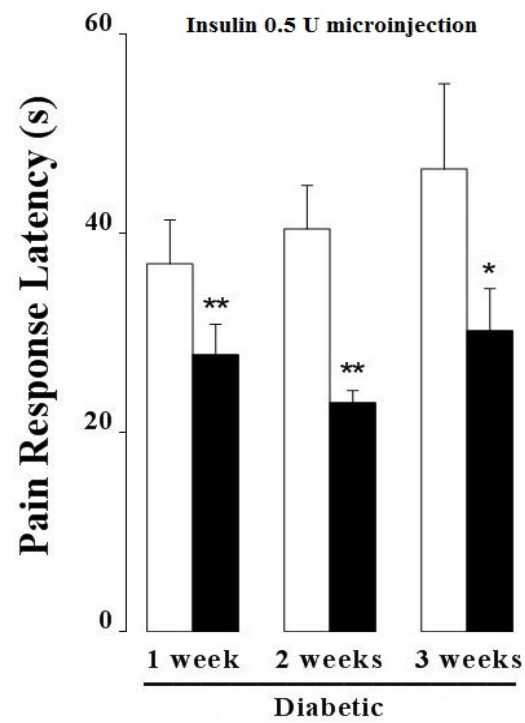

NEUR SCIENCE

Figure 3. Influence of the effective dose of insulin (0.5 IU) and the vehicle (saline) within the arcuate nucleus on pain response latency in hot plate test during three weeks in diabetic rats

The white columns display pain response latency before and the black ones display it after insulin injection. Each column indicates the Mean $\pm S E M$ value of each group.

${ }^{*} \mathrm{P}<0.05 ;{ }^{* *} \mathrm{P}<0.01$ in the $\mathrm{t}$-test.

and continued to increase in diabetic rats during the time in both hot-plate $\left(\mathrm{F}_{3,20}=8.179, \mathrm{P}<0.001\right.$; Figure $\left.5 \mathrm{~A}\right)$ and tail-flick $\left(\mathrm{F}_{3,20}=0.08911, \mathrm{P}<0.001\right.$; Figure $\left.5 \mathrm{~B}\right)$ tests.

\section{Discussion}

Results of the present study demonstrated that hypothalamic arcuate nucleus inhibition increased the thermal nociception. Insulin within the arcuate nucleus decreased the acute thermal pain perception, through the use of tail-flick and hot plate tests. STZ-induced diabetes made hypoalgesia in which the latency of these tests, progressively increased over time after induction of diabetes, and in the same animal group, intra-arcuate injection of insulin reduced the latency of thermal nociception, vice versa for the non-diabetic rats.

Neuropathy is one of the complications of diabetic patients (Schreiber, Nones, Reis, Chichorro, \& Cunha, 2015). It has a variety of manifestations, including hyperalgesia, allodynia, and hypoalgesia that occurs in advanced stages of diabetic neuropathy (MohammadiFarani, Sahebgharani, Sepehrizadeh, Jaberi, \& GhaziKhansari, 2010). Insulin has an analgesic effect such as modulating the analgesic system via modulating receptors of serotonin, opioids, and dopamine, as well as releasing serotonin and dopamine in the brainstem re- gions (Balali Dehkordi, Sajedianfard, \& Owji, 2017). The arcuate nucleus has POMC containing projections to the brainstem regions which modulate pain sensation in descending control of nociceptive, i.e., serotonergic and noradrenergic neurons in the raphe nuclei and the Periaqueductal Gray Area (PAG). Therefore, it plays an important role in controlling pain in brainstem areas (Sim \& Joseph, 1991). The arcuate neurons' terminals release opiocortin peptides, including beta-endorphin and adrenocorticotropic hormone which their receptors are abundant in raphe nuclei and PAG and cause inhibition of nociception (Sun \& Yu, 2005). In the present study, to confirm the role of the nociception inhibitory effect of the arcuate nucleus, injection of lidocaine into the arcuate nucleus caused hyperalgesia. Thus, the inhibition of this area causes allodynia that confirms the inhibitory role of arcuate nucleus in nociception.

So far, few studies have been conducted on the central effect of insulin as an analgesic hormone. Some studies showed that ICV injection of insulin reduced nociception in the formalin test which was inhibited by dopamine and serotonin antagonists (Takeshita \& Yamaguchi, 1997). Also, intra-spinal insulin-like growth factor 1 injection independently from the noradrenergic pathway reduces hyperalgesia (Bitar, Al-Bustan, Nehme, \& Pilcher, 1996). It seems that insulin has an analgesic effect due to the presence of high levels of receptors in the arcuate nucleus (Obici, Feng, Karkanias, Baskin, \& Rossetti, 2002). Systemic insulin administration increased the activity of the POMC neurons in the arcuate nucleus (Kim, Grace, Welch, Billington, \& Levine, 1999; Sim \& Joseph, 1991). Furthermore, it was demonstrated that long-term administration of insulin in healthy mice could increase the mRNA synthesis of opiocortin peptides in POMC neurons (Kim et al., 1999).

In the present study and a similar one (Sugimoto et al., 2008), in the first week after diabetes induction with STZ in the rats, acute thermal hypoalgesia was observed in the tail-flick and hot plate tests, and these reactions progressively increased over time. In this regard, various studies revealed that diabetes would cause hyperalgesia due to dysfunction of serotonin and dopamine and opioid peptides as well as the sensory disorders and changes in the mechanism of pain perception in diabetes, in contrast with the present study (Calcutt, Jorge, Yaksh, \& Chaplan, 1996; Sharma, Chopra, \& Kulkarni, 2007; Shirafkan, Sarihi, \& Komaki, 2013; Takeshita \& Yamaguchi, 1997). While in the advanced stages of diabetes, diabetic thermal, or mechanical hypoalgesia are observed (Beiswenger, Calcutt, \& Mizisin, 2008; Bierhaus et al., 2004; Christianson, Ryals, McCarson, \& Wright, 2003 


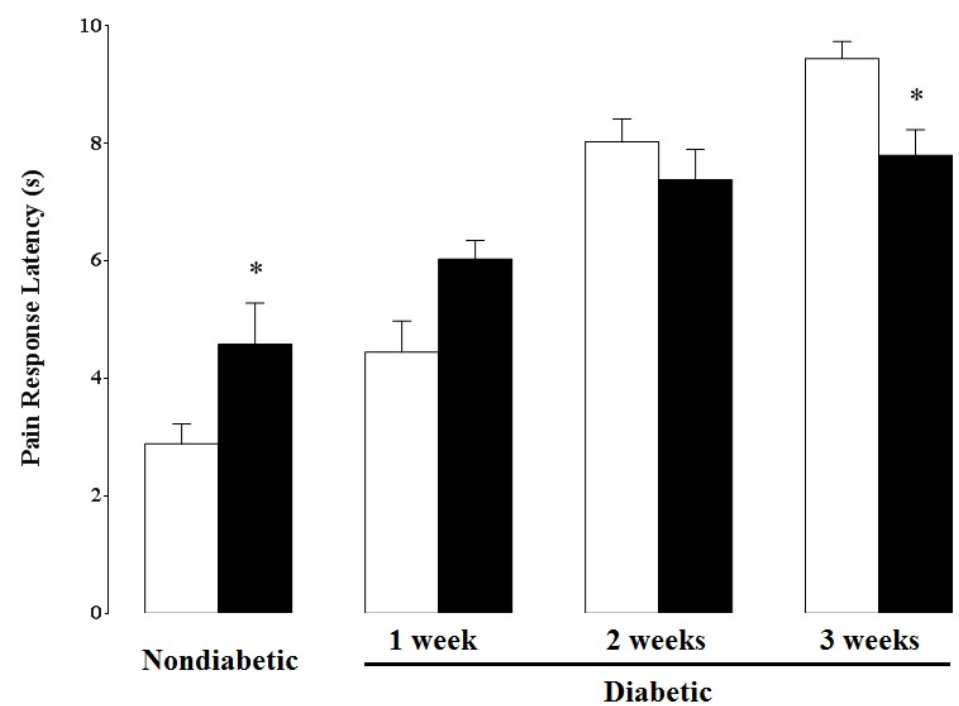

NEUR SCIENCE

Figure 4. Influence of the effective dose of insulin ( $0.5 \mathrm{IU})$ within the arcuate nucleus on pain response latency in the tail-flick test

During three weeks in non-diabetic and chronic diabetic rats the white columns display pain response latency before and the black ones display it after insulin injection. Each column indicates the Mean $\pm S E M$ value of each group.

${ }^{*} \mathrm{P}<0.05$ in the $\mathrm{t}$-test.

A 60

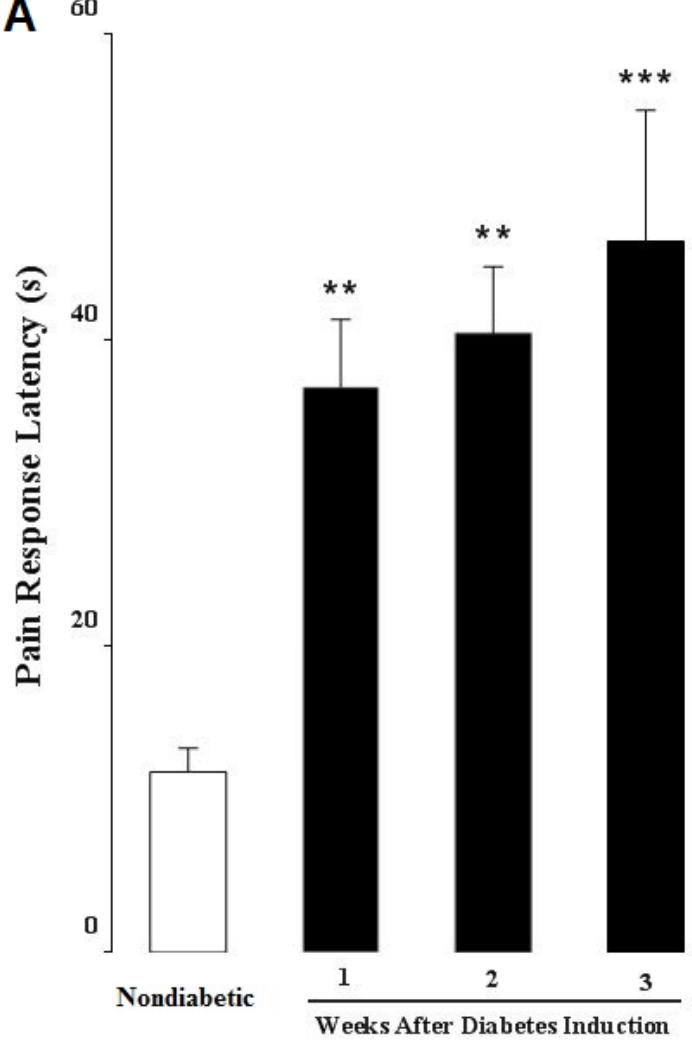

B

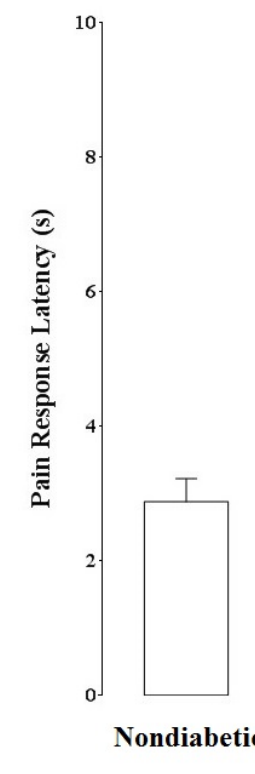

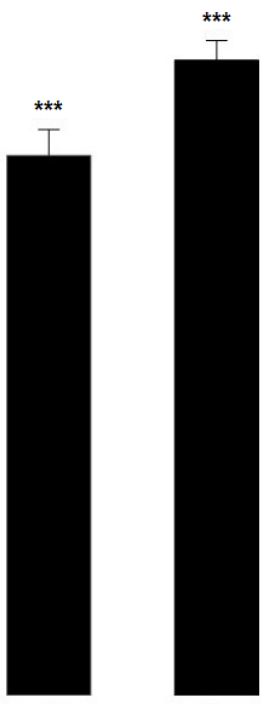

2

Weeks After Diabetes Induction NEUR SCIENCE

Figure 5. Influence of insulin-dependent diabetes (acute and chronic)

A: Pain response latency via hotplate; B: Tail-flick tests;

The white columns display pain response latency in non-diabetic rats and the black ones display it in diabetic ones in three weeks. Each column indicates the Mean+SEM value of each group.

** $\mathrm{P}<0.01$; and ${ }^{* * *} \mathrm{P}<0.001$ in 1-way ANOVA test. 
Chu et al., 2008; Kolta, Ngong, Rutledge, Pierzchala, \& Van Loon, 1996; Obrosova et al., 2008; Ohsawa, Miyata, Carlsson, \& Kamei, 2008; Ulugol et al., 2012; Urban et al., 2010). It seems that thermal hypoalgesia in the last stages of diabetes is induced due to the impairment of regeneration, neuronal degeneration, loss of sensory fibers, malfunction, and structural problems in small neurons' fibers (Sugimoto et al., 2008). In other words, neuropathy in the final stages involves a variety of dysfunctions in sensory neurons, including reduced conduction velocity which is related to progressive degeneration of total sensory fibers (Obrosova et al., 2008). However, thermal hypoalgesia in the early stages of diabetes, which was shown in the present study as well as others (Sugimoto et al., 2008; Urban et al., 2010), is caused by altered nociception and a disruption in the processing of sensory neuron information. Another reason for increasing the threshold of pain perception in the early stages of diabetic neuropathy is the impairment of the epidermal nociceptors functions before the loss of peripheral terminals in sensory neurons. The abnormal status of neurotransmitters in the nociceptors is also another cause of hypoalgesia in the early stages of diabetes (Beiswenger et al., 2008; Sugimoto et al., 2008).

In the present study, intra-arcuate nucleus injection of insulin increased the threshold of acute thermal pain in the healthy rats but reduced thermal hypoalgesia in STZinduced diabetic rats. In our study, single-dose insulin injection in the first, second, and third weeks after diabetes induction, probably cannot influence the biosynthesis of the myelin sheath and improve the signal conduction velocity in damaged nerves (Ohsawa et al., 2008). Perhaps, the improvement of the insulin receptor signaling in the arcuate nucleus following the insulin injection could have altered the balance of pain and non-pain neurotransmitters.

There are many insulin receptors on both neuropeptide $\mathrm{Y}$ and POMC neurons in the arcuate nucleus (Obici et al., 2002). Thus, any change in the release of beta-endorphin from POMC terminals can modulate the output of serotonergic fibers of the raphe nucleus (Hirosawa et al., 2008; Kombian \& Colmers, 1992; Obici et al., 2002). Some studies showed that insulin normalizes the serotonin and norepinephrine levels in the brainstem (de Silva, 2010). It was demonstrated that intranasal insulin injection influenced insulin secretion in the pancreas via its receptors in the hypothalamus (Kullmann et al., 2017). Fox et al. believed that changes in the content of neuronal growth factors and morphological changes in sensory neurons in diabetic models did not occur until the third week after diabetes induction (Fox, Eastwood,
Gentry, Manning, \& Urban, 1999). In the early stages after diabetes induction, changes in response to pain tests were associated with biochemical changes. Although hyperglycemia can play a role in the development of neuropathy, there was no correlation between the threshold of perceived thermal pain and hyperglycemia in diabetic -nd control animals (Piercy et al., 1999). In other words, the time of induction of biochemical and morphological changes in the nociception system changes the results and responses to pain tests, depending on different studies with different designs. To say some, age, sex, type, and race of animals, diabetes duration, use of different noxious stimulus in pain tests, duration of treatment with insulin, multiple doses of insulin treatment, method of insulin administration (peripherally or centrally), and many other things related to the design of the study would change the outcomes.

In conclusion, intra-arcuate nucleus injection of insulin produced acute thermal hypoalgesia in non-diabetic rats. Insulin reduced the thermal pain threshold in diabetic rats, which was time-dependent. However further studies on the mechanism of intra-arcuate nucleus insulin effect on reducing diabetic's hypoalgesia are needed.

\section{Ethical Considerations}

\section{Compliance with ethical guidelines}

This study was approved by the Ethics Committee of Babol University of Medical Sciences (Code: MUBABOL.HRI.REC.1397.77).

\section{Funding}

The present project was funded by the Neuroscience Research Center, Health Research Institute, Babol University of Medical Sciences (Grant No.: 9603917).

\section{Authors' contributions}

Study design, participation in experimental procedures, data analyze, drawing the diagrams, and Writing - original draft: Hossein Khaleghzadeh-Ahangar; Writing original draft: Forouzan Sadeghimahalli; Participation in experimental procedures: Shaghayegh Khandan; Preparing materials: Sima Shahabi; Preparing materials and Writing - original draft: Aliakbar Moghadamnia.

\section{Conflict of interest}

The authors declared no conflict of interest. 


\section{Acknowledgments}

The authors would like to appreciate dr. Ghadimi, the Research Deputy of Babol University of Medical Sciences, for his kind support for purchasing the tail-flick instrument and dr. Ashrafpour providing the glucometer kit. We also thank Professor Haghparast for his helpful comments on the experimental design.

\section{References}

Balali Dehkordi, Sh., Sajedianfard, J., \& Owji, A. A. (2017). The effect of intra-cerebroventricular injection of insulin on nociception of formalin test in non-diabetic and short-term diabetic rat models. Iranian Journal of Veterinary Research, 18(2), 108-12. [PMID] [PMCID]

Bayat, A. H., \& Haghparast, A. (2015). Effect of insulin deficiency on the rewarding properties of methamphetamine in streptozotocin-induced diabetic rats. Pharmacology Biochemistry and Behavior, 128, 8-13. [DOI:10.1016/j.pbb.2014.11.008] [PMID]

Beiswenger, K. K., Calcutt, N. A., \& Mizisin, A. P. (2008). Dissociation of thermal hypoalgesia and epidermal denervation in streptozotocin-diabetic mice. Neuroscience Letters, 442(3), 267-72. [DOI:10.1016/j.neulet.2008.06.079] [PMID] [PMCID]

Bierhaus, A., Haslbeck, K. M., Humpert, P. M., Liliensiek, B., Dehmer, T., \& Morcos, M., et al. (2004). Loss of pain perception in diabetes is dependent on a receptor of the immunoglobulin superfamily. The Journal of Clinical Investigation, 114(12), 1741-51. [DOI:10.1172/JCI18058] [PMID] [PMCID]

Bitar, M. S., \& Pilcher, C. W. T. (1997). Insulin-dependent attenuation in a2-adrenoreceptor-mediated nociception in experimental diabetes. Pharmacology Biochemistry and Behavior, 56(1), 15-20. [DOI:10.1016/S0091-3057(96)00129-3]

Bitar, M. S., Al-Bustan, M., Nehme, C. L., \& Pilcher, C. W. T. (1996) Antinociceptive action of intrathecally administered IGF-I and the expression of its receptor in rat spinal cord. Brain Research, 737(1-2), 292-4. [DOI:10.1016/0006-8993(96)00747-0]

Calcutt, N. A., Jorge, M. C., Yaksh, T. L., \& Chaplan, S. R. (1996) Tactile allodynia and formalin hyperalgesia in streptozotocin-diabetic rats: Effects of insulin, aldose reductase inhibition and lidocaine. Pain, 68(2-3), 293-9. [DOI:10.1016/S0304-3959(96)03201-0]

Carr, D. B., \& Goudas, L. C. (1999). Acute pain. The Lancet, 353(9169), 2051-8. [DOI:10.1016/S0140-6736(99)03313-9]

Christianson, J. A., Ryals, J. M., McCarson, K. E., \& Wright, D. E. (2003). Beneficial actions of neurotrophin treatment on diabetesinduced hypoalgesia in mice. The Journal of Pain, 4(9), 493-504. [DOI:10.1016/j.jpain.2003.07.002] [PMID]

Chu, Q., Moreland, R., Yew, N. S., Foley, J., Ziegler, R., \& Scheule, R. K. (2008). Systemic insulin-like growth factor-1 reverses hypoalgesia and improves mobility in a mouse model of diabetic peripheral neuropathy. Molecular Therapy, 16(8), 1400-8. [DOI:10.1038/mt.2008.115] [PMID]
Courteix, C., Bardin, M., Chantelauze, C., Lavarenne, J., \& Eschalier, A. (1994). Study of the sensitivity of the diabetes-induced pain model in rats to a range of analgesics. Pain, 57(2), 153-60. [DOI:10.1016/0304-3959(94)90218-6]

de Silva, L. J. V. (2010). Central effects of insulin and IGF1 in diabetic neuropathy [MSc. thesis]. Aveiro: Universidade de Aveiro; 2010. https://www.researchgate.net/publication/271574522

Dickenson, A. H. (1995). Central acute pain mechanisms. Annals of Medicine, 27(2), 223-7. [DOI:10.3109/07853899509031963] [PMID]

Erami, E., Azhdari-Zarmehri, H., Ghasemi-Dashkhasan, E., Esmaeili, M. H., \& Semnanian, S. (2012). Intra-paragigantocellularis lateralis injection of orexin-A has an antinociceptive effect on hot plate and formalin tests in rat. Brain Research, 1478, 16-23. [DOI:10.1016/j.brainres.2012.08.013] [PMID]

Fox, A., Eastwood, C., Gentry, C., Manning, D., \& Urban, L. (1999). Critical evaluation of the streptozotocin model of painful diabetic neuropathy in the rat. Pain, 81(3), 307-16. [DOI:10.1016/S03043959(99)00024-X]

Fuchs, D., Birklein, F., Reeh, P. W., \& Sauer, S. K. (2010). Sensitized peripheral nociception in experimental diabetes of the rat. Pain 151(2), 496-505. [DOI:10.1016/j.pain.2010.08.010] [PMID]

Hirosawa, M., Minata, M., Harada, K. H., Hitomi, T., Krust, A., \& Koizumi, A. (2008). Ablation of Estrogen Receptor alpha (ERa) prevents upregulation of POMC by leptin and insulin Biochemical and Biophysical Research Communications, 371(2), 320-3. [DOI:10.1016/j.bbrc.2008.04.073] [PMID]

Kim, E. M., Grace, M. K., Welch, C. C., Billington, C. J., \& Levine, A. S. (1999). STZ-induced diabetes decreases and insulin normalizes POMC mRNA in arcuate nucleus and pituitary in rats. American Journal of Physiology-Regulatory, Integrative and Comparative Physiology, 276(5), R1320-6. [DOI:10.1152/ajpregu.1999.276.5.R1320] [PMID]

Kolta, M., Ngong, J., Rutledge, L., Pierzchala, K., \& Van Loon, G. (1996). Endogenous opioid peptide mediation of hypoalgesic response in long-term diabetic rats. Neuropeptides, 30(4), 335-44. [DOI:10.1016/S0143-4179(96)90022-0]

Kombian, S. B., \& Colmers, W. F. (1992). Neuropeptide Y selectively inhibits slow synaptic potentials in rat dorsal raphe nucleus in vitro by a presynaptic action. Journal of Neuroscience, 12(3), 1086-93. [DOI:10.1523/JNEUROSCI.12-03-01086.1992] [PMID] [PMCID]

Kullmann, S., Fritsche, A., Wagner, R., Schwab, S., Häring, H. U., \& Preissl, H., et al. (2017). Hypothalamic insulin responsiveness is associated with pancreatic insulin secretion in humans. Physiology \& Behavior, 176, 134-8. [DOI:10.1016/j.physbeh.2017.03.036] [PMID]

Lorenzo, C., Serrano-Ríos, M., Martínez-Larrad, M. T., GonzálezSánchez, J. L., Seclén, S., \& Villena, A., et al. (2006). Geographic variations of the international diabetes federation and the national cholesterol education program-adult treatment panel III definitions of the metabolic syndrome in nondiabetic subjects. Diabetes Care, 29(3), 685-91. [DOI:10.2337/diacare.29.03.06.dc051796] [PMID]

Mohammadi-Farani, A., Sahebgharani, M., Sepehrizadeh, Z., Jaberi, E., \& Ghazi-Khansari, M. (2010). Diabetic thermal hyperalgesia: Role of TRPV1 and CB1 receptors of periaqueductal gray. Brain Research, 1328, 49-56. [DOI:10.1016/j.brainres.2010.02.077] [PMID] 
Obici, S., Feng, Z., Karkanias, G., Baskin, D. G., \& Rossetti, L. (2002). Decreasing hypothalamic insulin receptors causes hyperphagia and insulin resistance in rats. Nature Neuroscience, 5(6), 566-72. [DOI:10.1038/nn0602-861] [PMID]

Obrosova, I. G., Xu, W., Lyzogubov, V. V., Ilnytska, O., Mashtalir, N., \& Vareniuk, I., et al. (2008). PARP inhibition or gene deficiency counteracts intraepidermal nerve fiber loss and neuropathic pain in advanced diabetic neuropathy. Free Radical Biology and Medicine, 44(6), 972-81. [DOI:10.1016/j.freeradbiomed.2007.09.013] [PMID] [PMCID]

Ohsawa, M., Miyata, S., Carlsson, A., \& Kamei, J. (2008). Preventive effect of acetyl-L-carnitine on the thermal hypoalgesia in streptozotocin-induced diabetic mice. European Journal of Pharmacology, 588(2-3), 213-6. [DOI:10.1016/j.ejphar.2008.04.029] [PMID]

Paxinos, G., \& Watson, C. (2006). The rat brain in stereotaxic coordinates. Hard cover edition. Amsterdam: Elsevier.

Piercy, V., Banner, S. E., Bhattacharyya, A., Parsons, A. A., Sanger, G. J., \& Smith, S. A., et al. (1999). Thermal, but not mechanical, nociceptive behavior is altered in the Zucker Diabetic Fatty rat and is independent of glycemic status. Journal of Diabetes and its Complications, 13(3), 163-9. [DOI:10.1016/S10568727(99)00034-3]

Przewłocki, R., \& Przewłocka, B. (2001). Opioids in chronic pain. European Journal of Pharmacology, 429(1-3), 79-91. [DOI:10.1016/ S0014-2999(01)01308-5]

Romanovsky, D., Cruz, N. F., Dienel, G. A., \& Dobretsov, M. (2006). Mechanical hyperalgesia correlates with insulin deficiency in normoglycemic streptozotocin-treated rats. Neurobiology of Disease, 24(2), 384-94. [DOI:10.1016/j.nbd.2006.07.009] [PMID]

Sadeghi, S., Reisi, Z., Azhdari-Zarmehri, H., \& Haghparast, A. (2013). Involvement of orexin-1 receptors in the ventral tegmental area and the nucleus accumbens in antinociception induced by lateral hypothalamus stimulation in rats. Pharmacology Biochemistry and Behavior, 105, 193-8. [DOI:10.1016/j. pbb.2013.02.011] [PMID]

Sadeghimahalli, F., Khaleghzadeh-Ahangar, H., \& Baluchnejadmojarad, T. (2019). Role of prostaglandins in the vasodilator effect of the aqueous extract from Artemisia annua plant in Streptozotocin-induced diabetic rats. Annual Research E Review in Biology, 31(6), 1-10. [DOI:10.9734/arrb/2019/v31i630069]

Schreiber, A. K., Nones, C. F. M., Reis, R. C., Chichorro, J. G., \& Cunha, J. M. (2015). Diabetic neuropathic pain: Physiopathology and treatment. World Journal of Diabetes, 6(3), 432-44. [DOI:10.4239/wjd.v6.i3.432] [PMID] [PMCID]

Schulingkamp, R., Pagano, T., Hung, D., \& Raffa, R. (2000). Insulin receptors and insulin action in the brain: Review and clinical implications. Neuroscience E Biobehavioral Reviews, 24(8), 855-72. [DOI:10.1016/S0149-7634(00)00040-3]

Sharma, S., Chopra, K., \& Kulkarni, S. K. (2007). Effect of insulin and its combination with resveratrol or curcumin in attenuation of diabetic neuropathic pain: Participation of nitric oxide and TNF-alpha. Phytotherapy Research, 21(3), 278-83. [DOI:10.1002/ptr.2070] [PMID]

Shirafkan, T., Sarihi, A., \& Komaki, A. R. (2013). [Role of capsaicin receptors in periaqueductal gray on pain modulation in diabetic rats (Persian)]. Feyz, 17(4), 345-51. http:/ / feyz.kaums. ac.ir/article-1-2018-en.html
Sim, L. J., \& Joseph, S. A. (1991). Arcuate nucleus projections to brainstem regions which modulate nociception. Journal of Chemical Neuroanatomy, 4(2), 97-109. [DOI:10.1016/08910618(91)90034-A]

Sugimoto, K., Rashid, I. B., Shoji, M., Suda, T., \& Yasujima, M. (2008). Early changes in insulin receptor signaling and pain sensation in streptozotocin-induced diabetic neuropathy in rats. The Journal of Pain, 9(3), 237-45. [DOI:10.1016/j. jpain.2007.10.016] [PMID]

Sun, Y. G., \& Yu, L. C. (2005). Interactions of galanin and opioids in nociceptive modulation in the arcuate nucleus of hypothalamus in rats. Regulatory Peptides, 124(1-3), 37-43. [DOI:10.1016/j.regpep.2004.06.023] [PMID]

Takeshita, N., \& Yamaguchi, I. (1997). Insulin attenuates formalin-induced nociceptive response in mice through a mechanism that is deranged by diabetes mellitus. Journal of Pharmacology and Experimental Therapeutics, 281(1), 315-21. [PMID]

Treede, R. D., Kenshalo, D. R., Gracely, R. H., \& Jones, A. K (1999). The cortical representation of pain. Pain, 79(2-3), 105-11. [DOI:10.1016/S0304-3959(98)00184-5]

Ulugol, A., Oltulu, C., Gunduz, O., Citak, C., Carrara, R., \& Shaqaqi, M. R., et al. (2012). 5-HT7 receptor activation attenuates thermal hyperalgesia in streptozocin-induced diabetic mice. Pharmacology Biochemistry and Behavior, 102(2), 344-8. [DOI:10.1016/j.pbb.2012.05.006] [PMID]

Urban, M. J., Li, C., Yu, C., Lu, Y., Krise, J. M., \& McIntosh, M P., et al. (2010). Inhibiting heat-shock protein 90 reverses sensory hypoalgesia in diabetic mice. ASN Neuro, 2(4), e00040. [DOI:10.1042/AN20100015] [PMID] [PMCID]

van Houten, M., Posner, B. I., Kopriwa, B. M., \& Brawer, J. R. (1980). Insulin binding sites localized to nerve terminals in rat median eminence and arcuate nucleus. Science, 207(4435), 1081-3. [DOI:10.1126/science.6986652] [PMID]

Yamamoto, T., Nozaki-Taguchi, N., \& Chiba, T. (2002). Analgesic effect of intrathecally administered orexin-A in the rat formalin test and in the rat hot plate test. British Journal of Pharmacology, 137(2), 170-6. [DOI:10.1038/sj.bjp.0704851] [PMID] [PMCID] 